\title{
Expression of phosphorylated Akt (pAkt) in gastric carcinoma predicts prognosis and efficacy of chemotherapy
}

\author{
Daiki Murakami, Shunichi Tsujitani, Tomohiro Osaki, Hiroaki Saito, Kuniyuki Katano, Shigeru Tatebe, \\ and MASAHIDE IKEGUCHI \\ Department of Surgery, Division of Surgical Oncology, Faculty of Medicine, Tottori University, 36-1 Nishi-cho, Yonago 683-8504, Japan
}

\begin{abstract}
Background. The Akt signaling pathway controls the survival and growth of human cancers. We investigated the expression of phosphorylated Akt (pAkt) in patients with gastric cancer.

Methods. The expression of pAkt was immunohistochemically examined in 140 gastric cancer patients who underwent a gastrectomy. The expression of pAkt was evaluated based on staining intensity, and staining was classified as negative or positive. We examined the expression of pAkt and its association with the clinicopathological findings, prognosis, depth of invasion, the expression of p53, and efficacy of oral fluorouracil chemotherapy after surgery.

Results. Expression of pAkt was positive in 81 (58\%) patients and negative in $59(42 \%)$ patients. There were no significant correlations between pAkt expression and the clinicopathological findings. The prognosis of patients with pAkt-negative tumors was superior to that of patients with pAkt-positive tumors, and the difference was significant for T3/T4 gastric cancer $(P<0.05)$. Among the patients with $T 3 / T 4$ gastric cancer, postoperative oral fluorouracil treatment was effective in those who were pAkt-positive. Multivariate analysis revealed that pAkt expression and lymph node metastasis were independent prognostic factors. In 88 patients with $\mathrm{T} 3$ gastric carcinoma who had undergone curative surgery, in whom we studied the prognostic impact of a combined analysis of pAkt and p53 expression, patients with both pAkt- and p53positive tumors showed a significantly poorer prognosis than patients with either or both pAkt- and p53-negative tumors $(P<0.05)$.

Conclusion. Our results indicate that pAkt expression may be useful for predicting the prognosis and efficacy of fluorouracil treatment in patients with gastric cancer.
\end{abstract}

Key words pAkt • Gastric carcinoma - Prognosis · Chemotherapy

Offprint requests to: $\mathrm{S}$. Tsujitani

Received: June 15, 2006 / Accepted: December 5, 2006

\section{Introduction}

Survival factors suppress intrinsic cell-death machinery and thereby prevent apoptosis, a naturally occurring cell-death process that is critical for the development of multicellular organisms [1]. Recently, a signaling pathway by which extracellular stimuli can suppress apoptosis has been characterized. Survival factors, such as insulin-like growth factor 1 (IGF1) and neurotrophins, bind to their cell surface receptors and trigger the activation of several kinases, including phosphatidylinositide 3-kinase (PI3K) [2].

PI3K regulates a vast array of fundamental cellular responses and plays a critical role in controlling the balance between cell survival and apoptosis [3]. In turn, this kinase leads to the activation of a serine/threonine kinase termed Akt. Akt, a key effector of PI3K in signaling cell survival, is phosphorylated in response to a variety of growth factors and interleukins through phosphatidylinositides converted by PI3K [4-7]. Three human isoforms of Akt have been identified; namely, Akt-1, -2, and -3 [8,9]. Activated Akt (pAkt) phosphorylates the proapoptotic Bcl-2 family member Bad, caspase-9, a forkhead family transcription factor, p53, and I-kappaB kinase (IKK), thereby preventing apoptosis and possibly leading to endothelial cell survival.

Blockage of the PI3K/Akt pathway has been reported to induce cancer cell apoptosis and tumor suppression in some human cancers [10-12]. Moreover, activation of Akt is correlated with a poor outcome in breast cancer [13]. However, the role of Akt in gastric cancer has not been evaluated immunohistochemically. In the present study, we immunohistochemically examined surgically resected gastric carcinomas for their expression of pAkt and its association with the clinicopathological findings, prognosis, and efficacy of oral fluorouracil chemotherapy after surgery. We also examined the expression of p53, which is activated downstream of the PI3K/Akt pathway. 


\section{Patients, materials, and methods}

\section{Patients and tissue samples}

Primary gastric adenocarcinoma specimens were obtained from 140 patients treated at the Department of Surgery, Tottori University of Medicine between 1984 and 1991. These patients were selected without any intention from the list of those who had undergone curative surgery. The patients' age, sex, tumor size, depth of invasion, pathological type, lymph node metastasis, and pathological stage were determined by a review of the medical records. The clinicopathological findings were determined according to the criteria of the Japanese Research Society for Gastric Cancer [14]. The patients were 84 men and 56 women, who ranged in age from 37 to 91 years (average, 70.8 years). Most of these patients had undergone D2 lymph node dissection. Some elderly patients and those with preoperative complications had been treated with D1 $+\beta$ dissection. None of the patients had undergone preoperative chemotherapy or radiotherapy. Adjuvant chemotherapy was routinely prescribed for all patients with advanced gastric cancer. Among the patients with T3/T4 disease, 61 had undergone postoperative chemotherapy with consecutive oral administration of uracil/tegafur at a dose of $300 \mathrm{mg}$ daily for 1 year, while 31 patients had refused or discontinued the chemotherapy. All the patients had been monitored for at least 5 years. The follow-up data, as well as the mortality data, were also retrieved from the clinical records. Informed consent was obtained from all the subjects and/or their guardians.

\section{Immunohistochemistry}

For the immunohistochemical analysis, formalin-fixed and paraffin-embedded specimens were processed using a streptavidin-biotin method (Histofine SAB-PO kit; Nichirei, Tokyo, Japan). Briefly, 4- $\mu$ m-thick serial sections were dewaxed in xylene, rehydrated in ethanol, and heated with DAKO target retrieval solution (DAKO, Carpinteria, CA, USA) in an autoclave for antigen retrieval. Endogenous peroxidase was blocked by incubation with $0.3 \%$ hydrogen peroxide in methanol for $15 \mathrm{~min}$. The tissue sections were then washed twice with phosphate-buffered saline (PBS) and preblocked with $10 \%$ goat serum in PBS for $60 \mathrm{~min}$. After the washing with PBS, the samples were incubated with an anti-phospho-Akt (Ser473) polyclonal antibody (Cell Signaling Technology, Beverly, MA, USA) at a dilution of $1: 100$ for $30 \mathrm{~h}$ at $4^{\circ} \mathrm{C}$. Next, the sections were washed three times in PBS and incubated with anti-rabbit immunoglobulins $(\operatorname{IgG}+\operatorname{IgA}+\operatorname{IgM})$ conjugated with biotin (Nichirei) for $60 \mathrm{~min}$, followed by incubation with a streptavidin-peroxidase complex (Nichirei) for another
$60 \mathrm{~min}$. After three further washes in PBS, a diaminobenzidine tetrahydrochloride working solution was applied. Finally, the slides were counterstained with methyl green. pAkt expression was evaluated based on the staining intensity and classified into three categories: (1) negative staining; (2) low expression (1\%-50\% of the carcinoma cells were positive); and (3) high expression ( $>50 \%$ of the carcinoma cells were positive).

Staining for p53 was performed in samples from patients with T3 disease, using an anti-p53 monoclonal antibody (BP-53; Novocastra Laboratories, Newcastle, UK) at a dilution of $1: 50$, using a method similar to that used for the pAkt staining. The staining patterns were classified according to a previous report [15], as follows: negative (negative or equivocal staining or $<20 \%$ of the cancer cells were positive) and positive ( $>20 \%$ of the cancer cells were positive).

\section{Statistical analysis}

Statistical analyses were carried out using the standard $\chi^{2}$ test and the Mann-Whitney $U$-test. The overall survival was estimated by the Kaplan-Meier method, and the equality of the survival curves was analyzed statistically by the log-rank test. For multivariate analysis, independent prognostic factors were determined using the Cox proportional hazards model with a stepwise procedure. Statistical significance was considered at $P<$ 0.05. A Macintosh personal computer system (Stat View Software; Abacus Concepts, Berkeley, CA, USA) was used for all statistical analyses.

\section{Results}

To determine whether pAkt was expressed in human gastric carcinoma, pAkt immunoreactivity was examined in 140 gastric carcinomas. As shown in Fig. 1, pAkt was predominantly localized in the cytoplasm of the cancer cells. Expression of pAkt was negative in 59 cases (42\%), low in 46 cases (33\%), and high in 35 cases $(25 \%)$. Next, we classified the patients into pAktnegative $(n=59)$ and pAkt-positive $(n=81)$ groups. The correlations between pAkt expression and clinicopathological variables in the 140 patients are shown in Table 1. Expression of pAkt showed no significant correlation with age, sex, tumor size, depth of invasion, lymph node metastasis, or pathological stage.

The estimated overall 5-year survival rates of patients with pAkt-negative tumors and pAkt-positive tumors were $75 \%$ and $56 \%$, respectively (Fig. 2). There was no significant difference in survival between the two groups. The 5-year survival rates of T1/T2 gastric cancer patients were $96 \%$ for pAkt-negative cases $(n=20)$ and $90 \%$ for pAkt-positive cases $(n=28)$, with no significant 

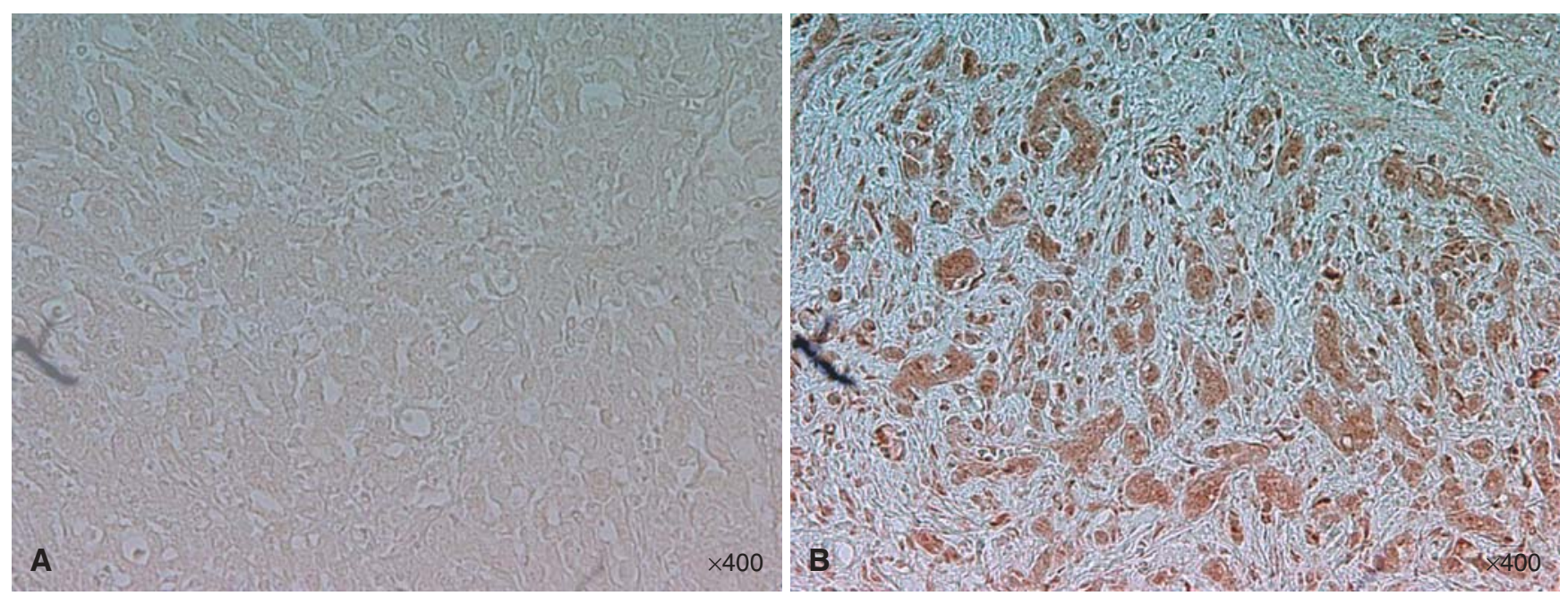

Fig. 1A,B. Typical immunohistochemical staining patterns of phosphorylated Akt (pAkt) in gastric cancer. A Negative staining; $\mathbf{B}$ positive staining. $\mathbf{A}$ and $\mathbf{B}, \times 400$

Table 1. Relationships between pAkt expression and clinicopathological findings

\begin{tabular}{|c|c|c|c|}
\hline Variable & pAkt-negative & pAkt-positive & $P$ value \\
\hline Age (years) & $66 \pm 11$ & $66 \pm 11$ & NS \\
\hline \multicolumn{4}{|l|}{ Sex } \\
\hline Male & 35 & 49 & \multirow[t]{2}{*}{ NS } \\
\hline Female & 24 & 32 & \\
\hline Tumor size $(\mathrm{cm})$ & $7.1 \pm 3.8$ & $7.1 \pm 3.7$ & NS \\
\hline \multicolumn{4}{|l|}{ Pathology } \\
\hline Differentiated & 36 & 40 & \multirow[t]{2}{*}{ NS } \\
\hline Undifferentiated & 23 & 41 & \\
\hline \multicolumn{4}{|l|}{ Depth of invasion } \\
\hline $\mathrm{T} 1$ & 13 & 21 & \multirow{4}{*}{ NS } \\
\hline $\mathrm{T} 2$ & 7 & 7 & \\
\hline $\mathrm{T} 3$ & 37 & 51 & \\
\hline $\mathrm{T} 4$ & 2 & 2 & \\
\hline \multicolumn{4}{|c|}{ Lymph node metastasis } \\
\hline Absent & 28 & 34 & \multirow[t]{2}{*}{ NS } \\
\hline Present & 31 & 47 & \\
\hline \multicolumn{4}{|l|}{ Lymphatic invasion } \\
\hline Absent & 21 & 33 & \multirow[t]{2}{*}{ NS } \\
\hline Present & 38 & 48 & \\
\hline \multicolumn{4}{|l|}{ Vascular invasion } \\
\hline Absent & 23 & 35 & \multirow[t]{2}{*}{ NS } \\
\hline Present & 36 & 46 & \\
\hline \multicolumn{4}{|l|}{ Pathological stage } \\
\hline I & 15 & 18 & \multirow{4}{*}{ NS } \\
\hline II & 5 & 9 & \\
\hline III & 37 & 46 & \\
\hline IV & 2 & 8 & \\
\hline
\end{tabular}

difference. In patients with T3/T4 gastric cancer, however, the 5-year survival rates were $68 \%$ for pAktnegative cases $(n=39)$ and $35 \%$ for pAkt-positive cases ( $n=53$; Fig. 3$)$. Therefore, patients with pAktnegative tumors survived for a significantly longer time than patients with pAkt-positive tumors $(P<0.05)$.

The relationship between pAkt expression and the efficacy of postoperative oral uracil/tegafur chemother- apy was analyzed. In patients with T3/T4 gastric cancer, the 5-year survival rates were $59 \%$ in those given uracil/tegafur $(n=61)$ and $39 \%$ in those not given the drugs $(n=31)$, with no significant difference. The 5-year survival rates for patients with pAkt-negative tumors did not differ significantly between those treated with uracil/tegafur (58\%) and those not given the drugs (42\%). Among patients with pAkt-positive tumors, however, 
the prognosis of those given uracil/tegafur was significantly better than that of those without chemotherapy $(P<0.05)$. Specifically, the 5-year survival rate of patients given uracil/tegafur was $63 \%$, whereas that of patients not given the drugs was $37 \%$ (Fig. 4).

Table 2 shows the results of a multivariate analysis using the Cox proportional hazards model and a stepwise procedure in patients with T3/T4 disease. The covariates included in the model were tumor size, depth of invasion, lymph node metastasis, pathological type, lymphatic invasion, venous invasion, uracil/tegafur che-

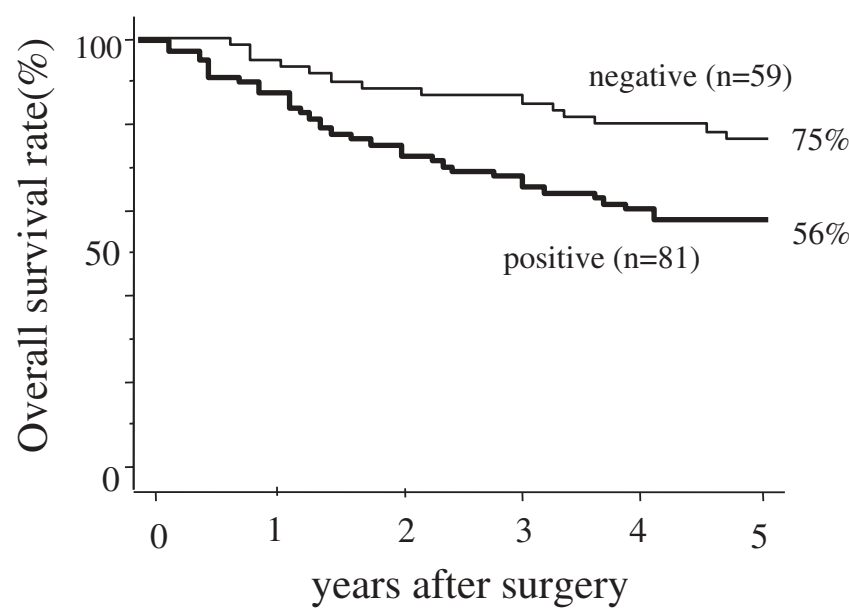

Fig. 2. Survival curves of patients with pAkt-negative and pAkt-positive tumors. There was no significant difference in survival between the two groups motherapy, and pAkt expression. The analysis revealed that lymph node metastasis and pAkt expression contributed independently to survival.

Next, we studied the prognostic impact of a combined analysis of pAkt and p53 expression in 88 patients with T3 gastric carcinoma who had undergone curative surgery. In these patients, the numbers of patients with pAkt (+)/p53(+), pAkt (+)/p53(-), pAkt (-)/p53(+), and pAkt (-)/p53(-) tumors were $20,24,19$, and 25 , respectively. There was no significant correlation between the expressions of pAkt and p53. The 5-year survival rate of patients with p53-positive tumors (47\%) was significantly poorer than that of patients with p53-negative tumors $(68 \% ; P<0.05)$. The 5 -year survival rates of patients with both pAkt- and p53-negative tumors, either pAkt- or p53-negative tumors, and both pAkt- and p53-positive tumors were $81 \%, 61 \%$, and $28 \%$, respectively (Fig. 5). A log-rank test revealed significant differences in survival between the three groups $(P<0.05$, respectively).

Table 2. Multivariate analysis of prognostic factors by the Cox proportional hazards model

\begin{tabular}{lccc}
\hline Variable & $\begin{array}{c}\text { Hazard } \\
\text { ratio }\end{array}$ & $95 \%$ CI & $P$ value \\
\hline pAkt expression & 0.227 & $0.119-0.433$ & 0.0032 \\
Lymph node metastasis & 1.555 & $0.987-2.451$ & 0.0053 \\
\hline
\end{tabular}
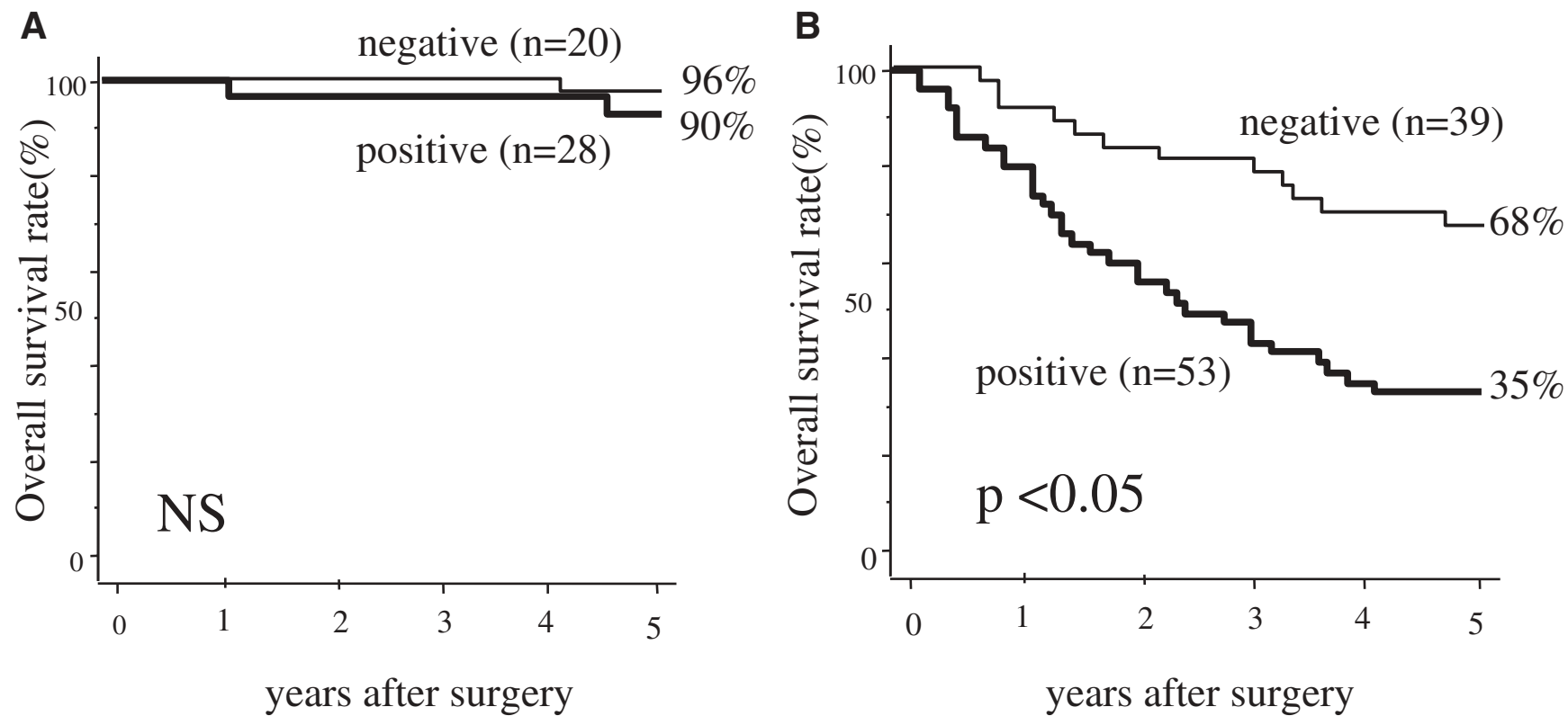

Fig. 3A,B. Survival curves of patients with gastric cancer according to pAkt status. A Patients with T1/T2 disease; B patients with T3/T4 disease. Patients with pAkt-negative tumors survived for a significantly longer time than patients with pAkt-positive tumors $(P<0.05)$ 
A

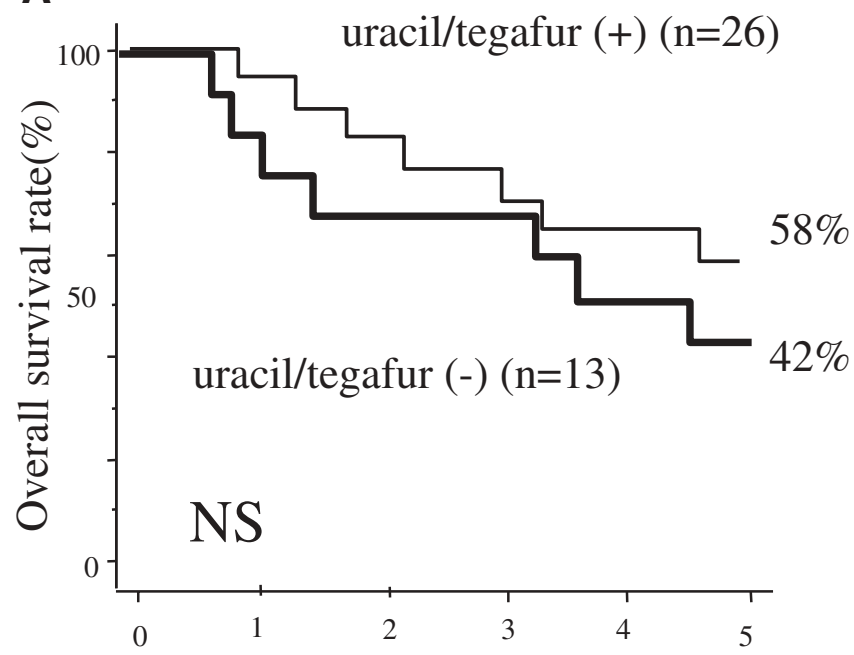

B

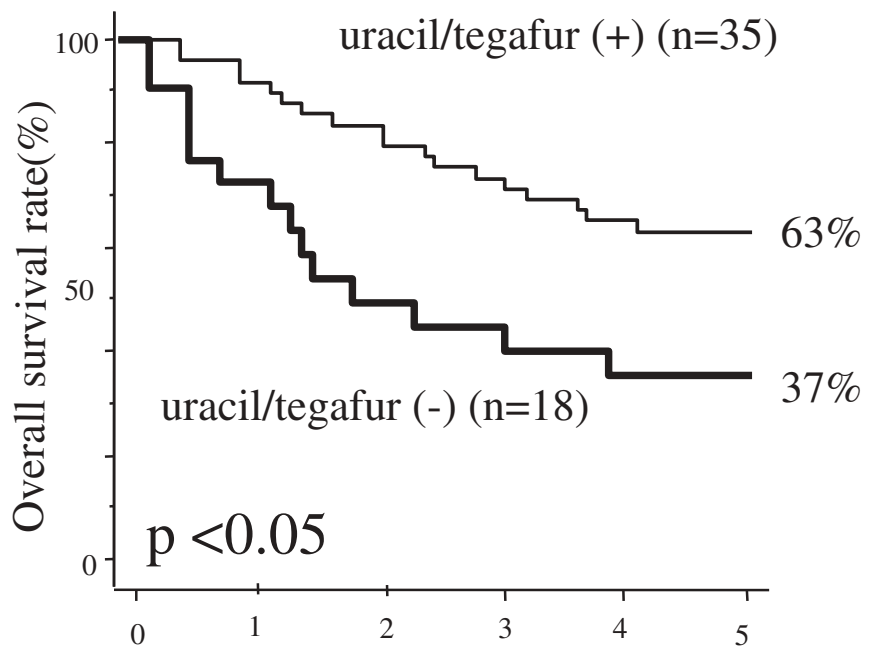

Fig. 4A,B. Survival curves of patients with T3/T4 gastric cancer, according to the administration of uracil/tegafur chemotherapy. A Patients with pAkt-negative tumors; B patients with pAkt-positive tumors. Uracil/tegafur chemotherapy was effective in patients with pAkt-positive tumors $(P<0.05)$, but not in patients with pAkt-negative tumors

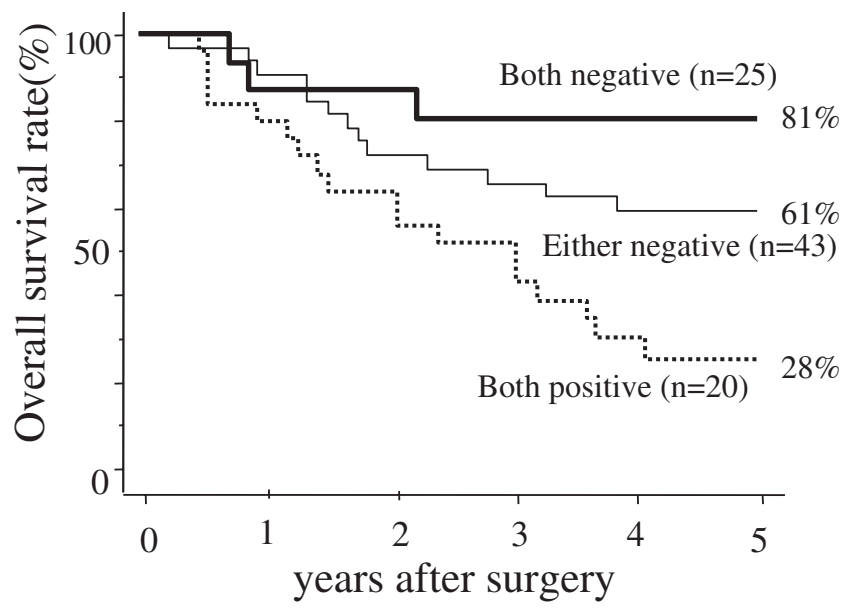

Fig. 5. Survival curves, according to pAkt/p53 status, of 88 patients with T3 gastric cancer who underwent curative surgery. Patients with both pAkt- and p53-positive tumors showed a significantly poorer prognosis than patients with either or both pAkt- and p53-negative tumors. There were significant differences between the three groups $(P<0.05$, respectively)

\section{Discussion}

In the present study, using immunohistochemistry, we have demonstrated the frequent occurrence of pAkt expression in surgically resected gastric cancers. Akt activation has been shown to protect cells from the apoptosis induced by withdrawing survival factors [16]. According to this antiapoptotic function, we hypothesized that patients with pAkt-positive gastric cancer would have a poorer prognosis than patients with pAkt- negative tumors. We found a significant association between increased pAkt expression and a poor prognosis for patients with T3/T4 gastric cancer, although no such correlation was detected for patients with T1/T2 disease. Grille et al. [17] reported that Akt activation in cancer cells conferred the motility required for tissue invasion and metastasis. Furthermore, pAkt was reported to be an important predictor of poor clinical outcome in breast and prostate cancers $[13,18]$. Although we did not find any significant correlations between pAkt protein expression and clinicopathological variables, our results are compatible with these previous reports, because a multivariate analysis revealed significance for the immunohistochemical evaluation of pAkt as well as lymph node metastasis, as an independent prognostic factor.

We further analyzed the relationship between pAkt expression and chemotherapy, because Akt has been reported to be a signal transduction protein that figures prominently in the mechanisms of carcinogenesis and chemoresistance [19-23]. Specifically, Akt plays a critical role in controlling the balance between cell survival and apoptosis [24]. Phosphorylation of Akt is promoted by phosphatidylinositides converted by PI3K products. Previous reports have shown that Akt delivers antiapoptotic survival signals by phosphorylating Bad and activating caspase-9 $[25,26]$. In a previous in vitro study, the chemotherapeutic agent SN-38 was found to induce apoptosis in human gastric cancer cells through inhibition of the PI3K-Akt pathway [27]. Furthermore, Oki et al. [28] demonstrated that pAkt expression was associated with increased resistance to multiple chemotherapeutic agents in gastric cancer patients, when the 
chemotherapeutic sensitivities were tested by MTT [3(4,5-dimetylthiazol-2-yl)-2,5-d-iphenyltetrazolium bromide] assays. Thus, Akt activation is presumed to lead to a poor prognosis and resistance to chemotherapeutic agents in gastric cancer. However, our results revealed that the prognosis of patients who received chemotherapy was significantly better than that of patients who did not receive chemotherapy, among pAkt-positive patients, but not among pAkt-negative patients. These results suggest that adjuvant chemotherapy may still be useful for patients with pAkt-positive gastric cancer. However, the number of patients in this study was too small for a definitive conclusion to be made. Applying formal statistics in retrospectively analyzed subgroups is potentially flawed and should be considered very cautiously. Recent data have suggested that Akt is activated in response to stresses induced by ultraviolet irradiation and chemotherapy [29-31]. Therefore, further studies regarding pAkt status in cancer tissues before and after chemotherapy are required.

Chemotherapeutic agents, such as cisplatin or paclitaxel, induce the expression of the tumor suppressor protein $\mathrm{p} 53$, together with an increase in the cyclin/ cyclin-dependent kinase inhibitor p21 protein, in order to maintain the correct temporal ordering of cell-cycle events [32]. Activation of Akt promotes the entry of $\mathrm{Mdm} 2$ into the nucleus and its interaction with $\mathrm{p} 53$. Binding of Mdm2 to p53 inhibits the transcriptional activity of p53 and targets it for proteasomal degradation. PTEN, which negatively regulates the survival signaling mediated by the PI3K/Akt pathway, can bind directly to p53 and prevent its degradation in a manner that is independent of its effects on Akt activation [33]. In the present study, we examined p53 expression in patients with T3 gastric cancer who had undergone curative surgery. Peritoneal dissemination is the most common cause of death in patients with gastric cancer, and is often found in T3 disease. Detailed investigation for prognostic factors in $\mathrm{T} 3$ gastric cancer is important to clarify the risk factors for peritoneal dissemination. Our study revealed that patients with both pAkt- and p53-positive tumors had a poorer prognosis than patients in the other groups. These results suggest that pAkt/p53 combined analysis may be a more useful prognostic indicator than pAkt alone in T3 gastric cancer. Therefore, further investigation of the relationship between the PI3K/Akt and p53/p21 pathways is required to fully understand the chemosensitivity of gastric cancer.

In conclusion, we have demonstrated, by immunohistochemistry of paraffin-embedded tissue sections, that pAkt expression plays an important role in predicting the survival and the efficacy of fluorouracil treatment in patients with T3 gastric cancer. Precise analysis of apoptotic signals via the PI3K/Akt and p53/p21 pathways could be a hallmark for optimal chemotherapy for gastric cancer.

\section{References}

1. Jacobson MD, Weil M, Raff MC. Programmed cell death in animal development. Cell 1997;88:347-54.

2. Fruman DA, Meyers RE, Cantley LC. Phosphoinositide kinases. Annu Rev Biochem 1998;67:481-507.

3. Franke TF, Kaplan DR, Cantley LC. PI3K: downstream AKTion blocks apoptosis. Cell 1997;88:435-7.

4. Cantley LC, Neel BG. New insights into tumor suppression: PTEN suppresses tumor formation by restraining the phosphoinositide 3-kinase/AKT pathway. Proc Natl Acad Sci USA 1999;96:4240-5.

5. Chang HW, Aoki M, Fruman D, Auger KR, Bellacosa A, Tsichlis PN, et al. Transformation of chicken cells by the gene encoding the catalytic subunit of PI 3-kinase. Science 1997;276: $1848-50$.

6. Conover CA, Bale LK, Durham SK, Powell DR. Insulin-like growth factor (IGF) binding protein-3 potentiation of IGF action is mediated through the phosphatidylinositol-3-kinase pathway and is associated with alteration in protein kinase B/AKT sensitivity. Endocrinology 2000;141:3098-103.

7. Datta SR, Brunet A, Greenberg ME. Cellular survival: a play in three Akts. Genes Dev 1999;13:2905-27.

8. Masure S, Haefner B, Wesselink JJ, Hoefnagel E, Mortier E, Verhasselt $\mathrm{P}$, et al. Molecular cloning, expression and characterization of the human serine/threonine kinase Akt-3. Eur J Biochem 1999;265:353-60.

9. Nakatani K, Sakaue H, Thompson DA, Weigel RJ, Roth RA. Identification of a human Akt3 (protein kinase B gamma) which contains the regulatory serine phosphorylation site. Biochem Biophys Res Commun 1999;257:906-10.

10. Yuan ZQ, Sun M, Feldman RI, Wang G, Ma X, Jiang C, et al. Frequent activation of AKT2 and induction of apoptosis by inhibition of phosphoinositide-3-OH kinase/Akt pathway in human ovarian cancer. Oncogene 2000;19:2324-30.

11. Page C, Lin HJ, Jin Y, Castle VP, Nunez G, Huang M, et al. Overexpression of Akt/AKT can modulate chemotherapyinduced apoptosis. Anticancer Res 2000;20:407-16.

12. Itoh $N$, Semba $S$, Ito $M$, Takeda $H$, Kawata $S$, Yamakawa $M$. Phosphorylation of Akt/PKB is required for suppression of cancer cell apoptosis and tumor progression in human colorectal carcinoma. Cancer 2002;94:3127-34.

13. Perez-Tenorio G, Stal O. Activation of AKT/PKB in breast cancer predicts a worse outcome among endocrine treated patients. Br J Cancer 2002;86:540-5.

14. Japanese Research Society for Gastric Cancer. Japanese classification of gastric carcinoma. Tokyo: Kanehara; 1995.

15. Gomyo Y, Ikeda M, Osaki M, Tatebe S, Tsujitani S, Ikeguchi M, et al. Expression of p21 (waf1/cip1/sdi1), but not p53 protein, is a factor in survival of patients with advanced gastric carcinoma. Cancer 1997;79:2067-72.

16. Downward J. Ras signalling and apoptosis. Curr Opin Genet Dev 1998;8:49-54.

17. Grille SJ, Bellacosa A, Upson J, Klein-Szanto AJ, van Roy F, Lee-Kwon W, et al. The protein kinase Akt induces epithelial mesenchymal transition and promotes enhanced motility and invasiveness of squamous cell carcinoma lines. Cancer Res 2003;63: $2172-8$.

18. Kreisberg JI, Malik SN, Prihoda TJ, Bedolla RG, Troyer DA, Kreisberg S, et al. Phosphorylation of Akt (Ser473) is an excellent predictor of poor clinical outcome in prostate cancer. Cancer Res 2004;64:5232-6.

19. Brognard J, Clark AS, Ni Y, Dennis PA. Akt/protein kinase B is constitutively active in non-small cell lung cancer cells and pro- 
motes cellular survival and resistance to chemotherapy and radiation. Cancer Res 2001;61:3986-97.

20. Brognard J, Dennis PA. Variable apoptotic response of NSCLC cells to inhibition of the MEK/ERK pathway by small molecules or dominant negative mutants. Cell Death Differ 2002;9: 893-904.

21. Clark AS, West K, Streicher S, Dennis PA. Constitutive and inducible Akt activity promotes resistance to chemotherapy, trastuzumab, or tamoxifen in breast cancer cells. Mol Cancer Ther 2002; 1:707-17.

22. Clark AS, West KA, Blumberg PM, Dennis PA. Altered protein kinase $\mathrm{C}(\mathrm{PKC})$ isoforms in non-small cell lung cancer cells: PKCdelta promotes cellular survival and chemotherapeutic resistance. Cancer Res 2003;63:780-6.

23. West KA, Castillo SS, Dennis PA. Activation of the PI3K/Akt pathway and chemotherapeutic resistance. Drug Resist Update 2002;5:234-48.

24. Balendran A, Casamayor A, Deak M, Paterson A, Gaffney P, Currie R, et al. PDK1 acquires PDK2 activity in the presence of a synthetic peptide derived from the carboxyl terminus of PRK2. Curr Biol 1999;9:393-404.

25. Cardone MH, Roy N, Stennicke HR, Salvesen GS, Franke TF, Stanbridge E, et al. Regulation of cell death protease caspase-9 by phosphorylation. Science 1998;282:1318-21.

26. Brunet A, Bonni A, Zigmond MJ, Lin MZ, Juo P, Hu LS, et al. Akt promotes cell survival by phosphorylating and inhibiting a Forkhead transcription factor. Cell 1999;96:857-68.
27. Yoshioka S. The PI3K-Akt pathway in SN-38-induced apoptosis in human gastric cancer cell lines. Yonago Acta Medica 2005;48: $7-16$.

28. Oki E, Baba H, Tokunaga E, Nakamura T, Ueda N, Futatsugi M, et al. Akt phosphorylation associates with LOH of PTEN and leads to chemoresistance for gastric cancer. Int J Cancer 2005;117: 376-80.

29. Wang HQ, Quan T, He T, Franke TF, Voorhees JJ, Fisher GJ. Epidermal growth factor receptor-dependent, NF-kappaBindependent activation of the phosphatidylinositol 3-kinase/Akt pathway inhibits ultraviolet irradiation-induced caspase-3, -8, and -9 in human keratinocytes. J Biol Chem 2003;278:4573745.

30. Ling X, Bernacki RJ, Brattain MG, Li F. Induction of survivin expression by Taxol (paclitaxel) is an early event, which is independent of Taxol-mediated G2/M arrest. J Biol Chem 2004; 279:15196-203.

31. Hayakawa J, Ohmichi M, Kurachi H, Kanda Y, Hisamoto K, Nishio Y, et al. Inhibition of BAD phosphorylation either at serine 112 via extracellular signal-regulated protein kinase cascade or at serine 136 via Akt cascade sensitizes human ovarian cancer cells to cisplatin. Cancer Res 2000;60:5988-94.

32. Gorospe M, Wang X, Holbrook NJ. Functional role of p21 during the cellular response to stress. Gene Expr 1999;7:377-85.

33. Mayo LD, Donner DB. A phosphatidylinositol 3-kinase/Akt pathway promotes translocation of Mdm2 from the cytoplasm to the nucleus. Proc Natl Acad Sci USA 2001;98:11598-603. 